\title{
Dietary patterns: a novel approach to examine the link between nutrition and cognitive function in older individuals
}

\author{
B. Allès ${ }^{1,2,3,4 *}$, C. Samieri ${ }^{1,2}$, C. Féart ${ }^{1,2}$, M.-A. Jutand ${ }^{1,2}$, D. Laurin ${ }^{3,4}$ and P. Barberger-Gateau ${ }^{1,2}$ \\ ${ }^{1}$ University of Bordeaux, ISPED, Centre INSERM U897-Epidemiologie-Biostatistique, F-33000 Bordeaux, France \\ ${ }^{2}$ INSERM, ISPED, Centre INSERM U897-Epidemiologie-Biostatistique, F-33000 Bordeaux, France \\ ${ }^{3}$ Centre d'excellence sur le vieillissement de Québec, Centre de recherche FRSQ du Centre hospitalier affilié universitaire \\ de Québec, Québec, Canada \\ ${ }^{4}$ Faculté de Pharmacie, Université Laval, Québec, Canada
}

(Submitted 18 November 2011 - Final revision received 23 April 2012 - Accepted 25 April 2012 - First published online 4 July 2012)

\section{Abstract}

Cognitive decline may lead to dementia whose most frequent cause is Alzheimer's disease (AD). Among the many potential risk factors of cognitive decline and $\mathrm{AD}$, diet raises increasing interest. Most studies considered diet in the frame of a single nutrient approach with inconsistent results. A novel approach to examine the link between nutrition and cognitive function is the use of dietary patterns. The aim of the present review was to update and complete the body of knowledge about dietary patterns in relationship with various cognitive outcomes in the elderly. Two approaches can be used: a priori and a posteriori patterns. A priori patterns are defined by the adhesion to a predefined healthy diet using a score such as the Mediterranean diet (MeDi) score, the Healthy Eating Index, the Canadian Healthy Eating Index, the French National Nutrition and Health Programme (Programme National Nutrition Santé) Guideline Score (PNNS-GS), the Recommended Food Score (RFS) and Dietary Approaches to Stop Hypertension (DASH). MeDi score, RFS, PNNS-GS and DASH have been associated with lower risks of cognitive impairment, cognitive decline, and dementia or AD. Principal components analysis, reduced rank regression and clustering methods allow the identification of 'healthy' patterns associated with lower risk of cognitive decline. However, some studies did not report any associations with cognitive outcomes and results are discordant especially regarding MeDi and the risk of dementia. Several methodological challenges should be overcome to provide a higher level of evidence supporting the development of nutritional policies to prevent cognitive decline and AD.

\section{Key words: Diet: Aged: Nutrition: Cognition: Alzheimer's disease}

\section{Introduction}

Cognitive decline is a progressive loss of cognitive functions including memory and other functions (for example, executive function), which may lead to dementia whose most frequent cause is Alzheimer's disease (AD). Many potential risk factors of cognitive decline and $\mathrm{AD}$ have been investigated, but, to date, the evidence concerning modifiable risk factors remains uncertain ${ }^{(1-3)}$. Areas that are presently considered to offer the most promising leads include nutritional patterns such as the Mediterranean diet $(\mathrm{MeDi})$ or any diets high in vegetables or $n$-3 PUFA ${ }^{(4)}$. However, the causal link between cognitive decline and diet has been mostly investigated in the context of randomised clinical trials (RCT) based on a single nutrient approach, which, to date, has given inconsistent results ${ }^{(5-8)}$. Indeed, observational data are not confirmed by RCT that have administered single nutrients, therefore raising evidence for using dietary pattern methods. Indeed, a combination of nutrients, provided by specific dietary patterns, may better prevent cognitive decline than nutrients taken in isolation ${ }^{(9)}$.

Dietary patterns are increasingly used in current research to better understand the link between diet and health outcomes. Such an approach is mainly justified by the existence, beyond specific actions of food components, of a 'food matrix' effect on biological systems, including antagonist,

\footnotetext{
Abbreviations: 3C, Three-City; 3MS, Modified Mini-Mental State; AD, Alzheimer's disease; CHAP, Chicago Health and Aging Project; CHEI, Canadian Healthy Eating Index; DASH, Dietary Approaches to Stop Hypertension; HDI, Healthy Diet Indicator; HEI, Healthy Eating Index; MCI, mild cognitive impairment, MeDi, Mediterranean diet; MMSE, Mini-Mental State Examination; PCA, principal components analysis; PNNS-GS, French National Nutrition and Health Programme (Programme National Nutrition Santé) Guideline Score; RCT, randomised clinical trial; RFS, Recommended Food Score; RRR, reduced rank regression; WHICAP, Washington Heights-Inwood Columbia Aging Project.
} 
additive and synergistic effects, which is different from specific actions of isolated food components ${ }^{(10-12)}$.

Two approaches can be used to derive dietary patterns: a priori and a posteriori. A priori patterns are defined by the adhesion of subjects to a pre-defined 'healthy' diet that can be summarised by a score. Several theoretically derived patterns, including the MeDi score ${ }^{(13)}$, or other scores based on dietary guidelines such as the Healthy Diet Indicator $(\mathrm{HDI})^{(14)}$, the Healthy Eating Index $(\mathrm{HEI})^{(15)}$, the Canadian Healthy Eating Index $(\mathrm{CHEI})^{(16)}$, the French National Nutrition and Health Programme (Programme National Nutrition Santé) Guideline Score (PNNS-GS) $^{(17)}$ and the Recommended Food Score $(\mathrm{RFS})^{(18)}$ have been used in relation with several brain ageing-related outcomes including cognitive impairment, cognitive decline and AD. A posteriori or empirically derived patterns reflect actual dietary intakes observed in a given population, independent of any assumption on their beneficial or harmful effects. They are obtained with complex multidimensional exploratory statistical analyses aiming at dimension reduction. Three methods have been used to study the link between food patterns and cognition: principal components analysis (PCA), reduced rank regression (RRR) and cluster analysis. A review by Gu \& Scarmeas ${ }^{(9)}$ reported associations between a priori and a posteriori dietary patterns and cognitive outcomes in older individuals. Since the publication of their review, substantial findings have been published concerning various a priori defined dietary patterns including the MeDi, PNNS-GS, HEI and CHEI and their association with cognitive decline. The aim of the present review was to update and complete the existing body of knowledge about dietary patterns in relationship with various cognitive outcomes in the elderly, emphasising the critical appraisal of statistical methods and discussing the challenges that future research will have to overcome in this field.

\section{Cognitive decline and nutrition: theoretical background}

A significant cognitive decline from a previous level of functioning is one of the main diagnostic criteria for dementia and $\mathrm{AD}$. In epidemiological studies, cognitive decline is commonly assessed on general neuropsychological tests such as the Mini-Mental State Examination $(\mathrm{MMSE})^{(19)}$ and its modified version $(3 \mathrm{MS})^{(20)}$ which assess global cognition function or with other neuropsychometric tests assessing specific cognitive domains (memory, attention, executive functions, etc.). $\mathrm{AD}$ is a complex multifactorial disease characterised by two neuropathological hallmarks: a dysfunction of the amyloid cascade inducing deposition of extracellular amyloid plaques in the brain ${ }^{(21,22)}$, and hyperphosphorylation of tau protein which forms intracellular neurofibrillary tangles ${ }^{(23)}$. In turn, these lesions lead to neurodegeneration, associated with increased inflammatory mechanisms and accruing oxidative stress ${ }^{(22)}$. According to experimental studies, nutrients could play a role in these mechanisms. Indeed, nutrients such as $n-3$ PUFA have potential beneficial effects against amyloidogenesis ${ }^{(24-28)}$, inflammation (with some inconsistent results) $^{(29,30)}$ and oxidative stress (when given at low dosages) ${ }^{(31)}$. DHA, a long-chain $n-3$ PUFA, is a major component of neuron membranes and has a biologically active role in maintaining optimal cell membrane structure and fluidity, and also cell function and responses ${ }^{(32)}$. Moreover, $n-3$ PUFA may modify the expression of genes that contribute to the regulation of inflammatory mechanisms by activating transcription factors (such as PPAR- $\gamma)^{(32)}$. In addition, antioxidant compounds such as vitamins $\mathrm{E}$ and $\mathrm{C}, \quad \beta$-carotene, polyphenols such as flavonoids, and Se also limit oxidative stress in nervous cells ${ }^{(33,34)}$. B vitamins are implicated in the regulation of homocysteine, which has a neurotoxic effect at high levels ${ }^{(35)}$. Vitamin D has been associated with neuroprotective, anti-inflammatory and antioxidant effects ${ }^{(36)}$. However, even if nutrients such as $n$-3 PUFA seem to be a key modulator in these mechanisms according to experimental studies on animal models, observational studies and clinical trials in human subjects remain inconclusive regarding their effects on cognitive decline $e^{(8,37,38)}$. The foremost limitation of these studies may be their inability to consider the previously mentioned concept of a synergy between foods and nutrients ${ }^{(10)}$. Jacobs \& Tapsell ${ }^{(12)}$ also highlighted that we do not have a complete knowledge of food composition and the effects of some of its components. For instance, the $n$-3 PUFA EPA and DHA are particularly vulnerable to lipid peroxidation because of their double bonds. A diet that provides simultaneously EPA and DHA along with dietary intakes of antioxidants and other protective nutrients including vitamins B, C, D and E, carotenoids and polyphenols, might be necessary to slow down neurodegeneration and the accompanying inflammatory and pro-oxidative phenomena ${ }^{(39)}$. In this context, a dietary pattern approach considering the potential interactions between nutrients appears to be especially promising in observational studies.

\section{Cognitive function and a priori methods for dietary pattern analysis}

These patterns are based on existing knowledge of diet-disease relationships, or on a priori criteria. Indexes were created to assess adherence to specific dietary guidelines for general healthy eating habits, or to very specific diets such as the MeDi. Further information on studies about the relationship between cognitive decline or impairment, $\mathrm{AD}$ and these a priori indexes is summarised in Table 1.

\section{The MeDi score}

The MeDi is characterised by high consumption of fruits, vegetables, legumes, cereals, fish, olive oil, and by low 


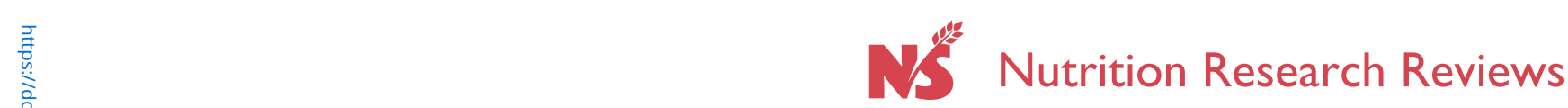

Table 1. Main studies using a priori methods in the context of cognitive decline and Alzheimer's disease (AD)

\begin{tabular}{|c|c|c|c|c|c|c|c|}
\hline $\begin{array}{l}\text { Reference, study, } \\
\text { country }\end{array}$ & Design & $\begin{array}{l}\text { Sample } \\
\text { size }\end{array}$ & $\begin{array}{l}\text { Mean age of the } \\
\text { sample at baseline } \\
\text { (years) }\end{array}$ & $\begin{array}{l}\text { Dietary intake } \\
\text { assessment method }\end{array}$ & $\begin{array}{l}\text { A priori dietary } \\
\text { pattern used }\end{array}$ & $\begin{array}{l}\text { Cognitive outcome, } \\
\text { measurement }\end{array}$ & Main results \\
\hline $\begin{array}{l}\text { Scarmeas et al. (2006) } \\
\text { WHICAP, USA }\end{array}$ & Nested case-control & 1984 & $76 \cdot 3$ & Semi-quantitative FFQ & MeDi score & $\begin{array}{l}\text { Incident dementia (DSM-III-R, } \\
\text { NINCDS-ADRDA) }\end{array}$ & $\begin{array}{l}\text { Highest adherence to } \mathrm{MeDi} \\
\text { associated with decreasing } \\
\text { risk of } \mathrm{AD} \text { (HR } 0.32 ; 95 \% \\
\mathrm{Cl} 0.17,0.59 \text { ) } \\
\text { Adjusting for cardiovascular vari- } \\
\text { ables led to no modification of } \\
\text { the association (HR 0.31; } \\
95 \% \mathrm{Cl} 0.16,0.58 \text { ) }\end{array}$ \\
\hline $\begin{array}{l}\text { Scarmeas et al. (2006)(55), } \\
\text { WHICAP, USA }\end{array}$ & $\begin{array}{l}\text { Cohort, longitudinal } \\
\text { Follow-up: } 4 \text { years }\end{array}$ & 2258 & 77.2 years & Semi-quantitative $\mathrm{FFQ}$ & MeDi score & $\begin{array}{l}\text { Incident dementia (DSM-III-R, } \\
\text { NINCDS-ADRDA) }\end{array}$ & $\begin{array}{l}\text { Each additional unit to MeDi } \\
\text { associated with less risk for } \\
\text { development of } \mathrm{AD} \text { (fully } \\
\text { adjusted model: } \mathrm{HR} 0.91 \text {; } \\
95 \% \mathrm{Cl} 0.83,0.98 \text { ) } \\
\text { Highest adherence to } \mathrm{MeDi} \rightarrow \\
\text { decreasing risk of } \mathrm{AD} \\
\text { (HR } 0.60,95 \% \mathrm{Cl} 0.42,0.87 \text { ) }\end{array}$ \\
\hline $\begin{array}{l}\text { Psaltopoulou et al. } \\
(2008)^{(49)}, \\
\text { EPIC-Greece, Greece }\end{array}$ & $\begin{array}{l}\text { Cohort, longitudinal } \\
\text { Follow-up: } 6-13 \text { years }\end{array}$ & 732 & $60+$ & Semi-quantitative FFQ & MeDi score & MMSE & $\begin{array}{l}\text { No statistically significant associ- }- \\
\text { ation with MeDi but borderline } \\
\text { significant for higher MMSE } \\
\text { for one-point increase in MeDi } \\
\text { score }(\beta=0.05 ; 95 \% \\
\text { Cl }-0.09,0.19 ; P=0.48)\end{array}$ \\
\hline $\begin{array}{l}\text { Scarmeas et al. (2009) } \\
\text { WHICAP, USA }\end{array}$ & $\begin{array}{l}\text { Cohort, Iongitudinal } \\
\text { Follow-up: } 4.5 \text { years }\end{array}$ & 1875 & 76.9 & Semi-quantitative $\mathrm{FFQ}$ & MeDi score & $\mathrm{MCl}$ and $\mathrm{MCl}$ conversion to $\mathrm{AD}$ & $\begin{array}{l}\text { Highest adherence to MeDi } \\
\text { associated with borderline } \\
\text { statistical significance for } \\
\text { decreasing risk of } \mathrm{MCl} \\
\text { (moderate stage of cognitive } \\
\text { decline, } \mathrm{HR} 0.72 ; 95 \% \\
\mathrm{Cl} 0.52,1.00 ; P=0.05 \text { ) } \\
\text { Highest adherence to MeDi led } \\
\text { to diminution of the risk of } \\
\text { conversion of } \mathrm{MCl} \text { to } \mathrm{AD} \\
\text { (HR } 0.52 ; 95 \% \mathrm{Cl} 0.30,0.91 \text { ) }\end{array}$ \\
\hline $\begin{array}{l}\text { Scarmeas et al. (2009) } \\
\text { WHICAP, USA }\end{array}$ & $\begin{array}{l}\text { Cohort, longitudinal } \\
\text { Follow-up: } 4.5 \text { years }\end{array}$ & 1880 & $77 \cdot 2$ & Semi-quantitative $\mathrm{FFQ}$ & MeDi score & $\begin{array}{l}\text { Incident dementia (DSM-III-R, } \\
\text { NINCDS-ADRDA) }\end{array}$ & $\begin{array}{l}\text { Highest adherence to MeDi } \\
\text { regardless of the protective } \\
\text { effect of physical activity } \\
\text { associated with decreased risk } \\
\text { of } \mathrm{AD} \text { (HR } 0.67 ; 95 \% \mathrm{Cl} 0.47 \text {, } \\
0.95 \text { ) }\end{array}$ \\
\hline $\begin{array}{l}\text { Féart et al. (2009) } \\
\text { 3C, France }\end{array}$ & $\begin{array}{l}\text { Cohort, longitudinal } \\
\text { Follow-up (median): } \\
\quad 4.1 \text { years }\end{array}$ & 1410 & $75 \cdot 9$ & $\mathrm{FFQ}, 24 \mathrm{~h}$ record & MeDi score & $\begin{array}{l}\text { MMSE, IST (semantic verbal } \\
\text { fluency, speed of verbal } \\
\text { production), BVRT (visual } \\
\text { memory), FCSRT (verbal } \\
\text { episodic memory) }\end{array}$ & $\begin{array}{l}\text { Highest MeDi scores associated } \\
\text { with fewer errors on MMSE } \\
(\beta=-0.006 ; 95 \% \mathrm{Cl}-0.01 \text {, } \\
-0.0003 ; P=0.04) \text { and slower } \\
\text { cognitive decline in the whole } \\
\text { study sample } \\
\text { No statistical association with } \\
\text { IST, BVRT, FCRST over time } \\
\text { in the whole study sample }\end{array}$ \\
\hline
\end{tabular}




\begin{tabular}{|c|c|c|c|c|c|c|c|}
\hline $\begin{array}{l}\text { Reference, study, } \\
\text { country }\end{array}$ & Design & $\begin{array}{l}\text { Sample } \\
\text { size }\end{array}$ & $\begin{array}{l}\text { Mean age of the } \\
\text { sample at baseline } \\
\text { (years) }\end{array}$ & $\begin{array}{l}\text { Dietary intake } \\
\text { assessment method }\end{array}$ & $\begin{array}{l}\text { A priori dietary } \\
\text { pattern used }\end{array}$ & $\begin{array}{l}\text { Cognitive outcome, } \\
\text { measurement }\end{array}$ & Main results \\
\hline $\begin{array}{l}\text { Tangney et al. (2011) }{ }^{(52)} \text {, } \\
\text { CHAP, USA }\end{array}$ & $\begin{array}{l}\text { Cohort, longitudinal } \\
\text { Follow-up: } 7.6 \text { years }\end{array}$ & 3790 & 75.4 & Semi-quantitative FFQ & HEI-2005 & $\begin{array}{l}\text { Global cognitive score including: } \\
\text { MMSE and SDMT }\end{array}$ & $\begin{array}{l}\text { No statistical association } \\
\text { between } \mathrm{HEI}-2005 \text { score and } \\
\text { cognitive change }(\beta=0.0002 \text {; } \\
P=0.214)\end{array}$ \\
\hline $\begin{array}{l}\text { Wengreen et al. (2009)(61), } \\
\text { Cache County, USA }\end{array}$ & $\begin{array}{l}\text { Cross-sectional } \\
\text { analysis } \\
\text { Follow-up: } 11 \text { years }\end{array}$ & 3634 & $\begin{array}{l}\text { Range } 73 \cdot 8-75 \cdot 6 \\
\text { depending on } \\
\text { quartile of RFS }\end{array}$ & FFQ & $\begin{array}{l}\text { RFS and } \\
\text { non-RFS }\end{array}$ & $3 M S$ & $\begin{array}{l}\text { At baseline: higher MMSE in 4th } \\
\text { quartile of RFS } \\
\text { 11-year follow up: less decline in } \\
\text { 4th quartile of MMSE (quartile } \\
\text { 4, mean - } 3.41 \text { (SD } 0.79 \text { ); } \\
\text { quartile } 1 \text {, mean }-5.15 \\
\text { (SD 0.69)) } \\
\text { No statistical association with } \\
\text { non-RFS }\end{array}$ \\
\hline $\begin{array}{l}\text { Shatenstein et al. }(2012)^{(16)} \\
\text { NuAge, Canada }\end{array}$ & $\begin{array}{l}\text { Cohort } \\
\text { Longitudinal 4-year } \\
\quad \text { follow-up }\end{array}$ & 1488 & $\begin{array}{l}\text { 74. } 1 \text { for men and } \\
74.4 \text { for women }\end{array}$ & $\mathrm{FFQ}$ & CHEI & $3 \mathrm{MS}$ & $\begin{array}{l}\text { No association between } \mathrm{CHEI} \\
\text { and cognitive decline over } \\
\text { time }(\beta=-0.001 ; P=0.336)\end{array}$ \\
\hline $\begin{array}{l}\text { Kesse-Guyot et al. } \\
(2011)^{(59)}, \\
\text { SU.VI.MAX 2, France }\end{array}$ & $\begin{array}{l}\text { Cross-sectional } \\
\text { analysis }\end{array}$ & 2135 & 52.6 & $24 \mathrm{~h}$ record & (PNNS-GS) & $\begin{array}{l}\text { Battery of neurocognitive tests } \\
\text { Principal components analysis to } \\
\text { provide summary scores that } \\
\text { accounted for correlations } \\
\text { among cognitive tests }\end{array}$ & $\begin{array}{l}\text { In fully adjusted models: increase } \\
\text { in PNNS-GS statistically sig- } \\
\text { nificantly associated with } \\
\text { higher episodic memory } \\
(\beta=0.38 ; P<0.05) \text {, semantic } \\
\text { verbal fluency }(\beta=0.27 \\
P<0.05) \text { and phonemic flu- } \\
\text { ency }(\beta=0.25 ; P<0.05) \\
\text { Potential beneficial effect of mid- } \\
\text { life compliance with nutritional } \\
\text { guidelines on verbal memory, } \\
\text { a cognitive domain particularly } \\
\text { vulnerable to dementia }\end{array}$ \\
\hline $\begin{array}{l}\text { Smith et al. }(2010)^{(67)} \text {, } \\
\text { DASH, USA }\end{array}$ & $\begin{array}{l}\mathrm{RCT} \text { (4 months } \\
\text { follow-up) }\end{array}$ & 124 & $52 \cdot 3$ & $\mathrm{~N} / \mathrm{A}$ & DASH diet & $\begin{array}{l}\text { Battery of neurocognitive tests } \\
\text { for executive function, memory } \\
\text { and learning (six tests) and } \\
\text { psychomotor speed (two tests) }\end{array}$ & $\begin{array}{l}\text { DASH diet + weight manage- } \\
\text { ment: greater improvement in } \\
\text { executive function, memory } \\
\text { and learning (Cohen's } \\
d=0.562 ; P=0.008) \text { and psy- } \\
\text { chomotor speed (Cohen's } \\
d=0.480 ; P=0.023) \\
\text { DASH diet alone: better psycho- } \\
\text { motor speed (Cohen's } \\
d=0.440 ; P=0.036)\end{array}$ \\
\hline
\end{tabular}

WHICAP, Washington Heights-Inwood Columbia Aging project, MeDi, Mediterranean diet; DSM-III-R, Diagnostic and Statistical Manual of Mental Disorders, third edition revised; NINCDS-ADRDA, National Institute of Neurological and Communicative Disorders and Stroke and the Alzheimer's Disease and Related Disorders Association; HR, hazard ratio; EPIC, European Prospective Investigation into Cancer and Nutrition; MMSE, Mini-Mental State Examination; MCI, mild cognitive impairment; 3C, Three-City; IST, Isaacs Set Test; BVRT, Benton Visual Retention Test; FCSRT, Free and Cued Selective Reminding Test; CHAP, Chicago Health and Aging Project; SDMT, Symbol Digit Modalities Test; PATH, Personality and Total Health Through Life Project; HDI, Healthy Diet Indicator; HEl-2005, Healthy Eating Index-2005; RFS, Recommended Food Score; 3MS, Modified Mini-Mental State; NuAge, Québec Longitudinal Study on Nutrition and Successful Aging; CHEI, Canadian Healthy Eating Index; SU.VI.MAX 2, SUpplémentation en Vltamines et Minéraux Anti-oXydants (Supplementation with Antioxidant Vitamins and Minerals); PNNS-GS, French National Nutrition and Health Programme (Programme National Nutrition Santé) Guideline Score; DASH, Dietary Approaches to Stop Hypertension, RCT, randomised clinical trial; N/A, not applicable. 
consumption of meat and dairy products with a moderate consumption of wine ${ }^{(40-42)}$. The MeDi provides essential nutrient-rich foods, which could also be associated with protection against cognitive decline such as fruits and vegetables, fish, MUFA, PUFA and moderate wine consumption. Indeed, two recent reviews suggested that the MeDi could be associated with protective effects in pre-dementia and dementia syndromes ${ }^{(43,44)}$. Several MeDi scores have been proposed to evaluate the adherence to a MeDitype. They have been modified and adapted to populations or hypotheses since the original version from Trichopoulou et al. in $1995^{(13,42,45)}$.

For presumed beneficial food components (fruits and vegetables, olive oil or MUFA:SFA ratio, legumes, cereals, and fish), the MeDi score is computed with a value of 1 assigned to a subject whose consumption of the food group is above the sex-specific median of the population, and 0 if not. On the contrary, for meat and dairy products considered as detrimental: a score of 0 is assigned to a subject whose consumption is above the sex-specific median, and 1 if not. For alcohol or wine, a 'moderate consumption' is given a value of 1 . The MeDi score is the sum of these 'beneficial' and 'detrimental' components and usually ranges between 0 and 9. A higher MeDi score means higher adherence to a MeDi.

The MeDi score is the most frequently used a priori index in the context of cognitive decline or cognitive impairment. To our knowledge, only seven studies investigated this relationship, based on various subsets of five different epidemiological studies in the USA, France, Greece and Australia (Table 1). Scarmeas et al. ${ }^{(46)}$ were the first to report from the Washington Heights-Inwood Columbia Aging project (WHICAP), a prospective study of subjects aged $\geq 65$ years at baseline, that those in the highest MeDi score tertile had a $40 \%$ reduced risk for incident AD compared with subjects in the lowest one (hazard ratio $0.60 ; 95 \%$ CI $0.42,0.87$ ). In addition, they found a reduced risk for $\mathrm{AD}$ in a case-control study investigating the association between the MeDi score and the prevalence of $\mathrm{AD}$ at WHICAP baseline. Compared with the subjects in the lowest MeDi score tertile, those in the highest tertile had a lower risk of having AD (OR 0.32; 95\% CI 0.17, $0.59)^{(47)}$. However, this cross-sectional study is particularly prone to reverse causality, i.e. subjects with $\mathrm{AD}$ may have modified their diet as a consequence of their cognitive problems. Borderline decreased risk of mild cognitive impairment (MCI) for subjects in the middle and higher MeDi score tertiles compared with the lowest tertile were also observed in a subsample of the prospective WHICAP analysis (middle tertile: hazard ratio $0 \cdot 83,95 \%$ CI $0.62,1 \cdot 12$; higher tertile: hazard ratio $0.72,95 \%$ CI $0.52,1.00 ; p$ for trend $=0.05$ as compared with the lowest tertile) ${ }^{(48)}$. In Europe, Psaltopoulou et al. ${ }^{(49)}$ using data from the European Prospective Investigation into Cancer and Nutrition (EPIC)-Greece cohort (subjects $\geq 60$ years at baseline) found no association between MMSE score and MeDi adherence over time, but evidence of an inverse association between consumption of PUFA and seed oils and lower MMSE performances 6 to 12 years later, although no MMSE baseline measure was available. In the ThreeCity (3C) cohort study (subjects $\geq 65$ years at baseline), Féart et al. ${ }^{(50,51)}$ found that subjects with higher MeDi scores had a lower decline in MMSE performances over time $(P=0.04)$ while no association was observed with the evolution of verbal episodic memory, immediate visual memory, semantic verbal fluency or with risk of incident $\mathrm{AD}$ during the follow-up.

Based on a sample of the Chicago Health and Aging Project (CHAP) cohort (subjects $\geq 65$ years at baseline), Tangney et $a l .{ }^{(52)}$ found that the MeDi score either as a continuous variable, or its highest tertile, was significantly associated with lower decline of global cognitive function over time $(P=0.0009)$. A similar statistically significant association was observed when only wine was considered in the computation of the MeDi score $(P=0.0004)$, instead of total alcohol beverages.

Finally, a recent report from the Personality and Total Health (PATH) Through Life Project in Australia (60-64 years at baseline) showed no statistically significant association of adherence to the MeDi and cognitive decline $(P=0 \cdot 37)^{(53)}$

Given the present available published data, there exist some clues that the MeDi has protective effects against cognitive decline or dementia but results remain inconclusive so far (for recent reviews, see $\mathrm{Gu} \&$ Scarmeas $^{(9)}$, Sofi et $a l .{ }^{(41)}$, Solfrizzi et al. ${ }^{(44)}$, Féart et $a .^{(51)}$ and Barnes ${ }^{(54)}$ ). Methodological aspects partly explain these inconsistencies. Notably, the internal validity of the MeDi score could be questioned, given that two individuals with the same score may have different diets. Moreover, a major limitation to its external validity is that the MeDi score is based on the study sample medians, which vary across studies and thus can reflect different dietary intakes. For example, low vegetable consumers in France can be considered as high consumers in the $\mathrm{USA}^{(51)}$. In addition, the MeDi score does not take into account the amount of foods actually consumed but only their ranking relative to the sample median. Hence, a similar MeDi score does not correspond to identical quantities of foods across studies.

Second, food intakes are measured using different methods in the studies, more or less influencing the precision of the estimation. For example, Scarmeas et al. ${ }^{(55)}$ used a semi-quantitative $\mathrm{FFQ}^{(55)}$ for estimation of quantities of nutrients whereas Féart et al. ${ }^{(50)}$ used both a qualitative FFQ for food groups and a $24 \mathrm{~h}$ recall for the MUFA:SFA ratio and estimation of total energy intake. Other adaptations of the MeDi score may also limit the comparability between studies. For example, both the $3 \mathrm{C}$ and WHICAP studies used the ratio of MUFA:SFA intakes instead of the consumption of olive oil originally proposed $^{(51,55)}$. The item concerning moderate alcohol consumption is also very specific to each study. 
For example, in the French $3 \mathrm{C}$ study the investigators defined a moderate consumption as having a consumption of glasses of alcohol in the second quartile of distribution of total alcohol consumption in this population ${ }^{(50)}$, whereas in the US WHICAP study, a moderate consumption was a range of $0-30 \mathrm{~g}$ alcohol per $\mathrm{d}^{(47)}$. Moreover, the alcohol item was computed based on wine only in some studies, as suggested in the original Mediterranean pyramid of food groups, whereas other studies considered all alcoholic beverages as in the original definition of the MeDi score ${ }^{(42)}$. For example, in the CHAP study, the MeDi score was computed based on wine only, due to strong hypotheses on benefits of resveratrol found in wine but not in other alcoholic beverages ${ }^{(52)}$.

Finally, another limitation of the MeDi score is the consideration of dichotomous (beneficial $v$. detrimental) food groups, without weights assigned to the different food groups, assuming equal effects of each component in the quality of the diet. This is an uncertain hypothesis making the score based on strong a priori criteria.

\section{Healthy diet guidelines-based scores}

Healthy Diet Indicator. The HDI score is based on international dietary guidelines for the prevention of chronic diseases defined by the WHO in $1990^{(14)}$. The HDI ranges from 0 to 9 with a one-point rise for adherence to each of the following food group or nutrient WHO guideline criteria: SFA; PUFA; protein; complex carbohydrates; dietary fibres; fruits and vegetables; pulses, nuts and seeds; mono- and disaccharides; cholesterol. A higher HDI reflects a diet closer to the WHO dietary guidelines.

To date, the HDI has been studied in the context of cognitive impairment in two cross-sectional studies. First, Huijbregts et al. ${ }^{(56)}$ reported in the Seven Countries Study (subjects' age range 70-91 years) a borderline statistically significant association with lower risk of cognitive impairment (defined as MMSE < 23) in subjects with a high HDI score. However, depending on the country, results remain inconsistent in this study: only one cohort (Crevalcore, Italy) out of five assessed in this analysis found a statistically significant protective association against impairment of cognitive function after adjustment (OR 0.75; 95\% CI 0.58, 0.97). Second, in another cohort study from Pavia, Italy (subjects $\geq 65$ years), an inverse association between higher HDI score and cognitive decline (OR $0.85 ; 95 \%$ CI $0.77,0.88$ ) measured by the neuropsychological test, an extended version of the MMSE has been reported ${ }^{(57)}$.

Healthy Eating Index and Canadian Healthy Eating Index. The HEI 2005 is composed of twelve items reflecting diet quality according to 2005 Dietary Guidelines for Americans by sex and age ${ }^{(15)}$. Most of these guidelines are on a density basis, that is to say, a ratio to total energy intake. The score ranges between 0 and 100; a higher HEI reflects a diet that follows American guidelines for healthy eating better. Each item of the HEI is proportional to the extent to which the dietary guidelines are met. In the CHAP study, Tangney et al. ${ }^{(52)}$ did not find any relationship between this index and cognitive performances at baseline or with cognitive decline over time.

The CHEI proposed in 2005 is a nine-item score based on a computation similar to HEI 2005, but using the Canadian Dietary Guidelines ${ }^{(58)}$. The score also ranges between 0 and 100; a higher CHEI reflects a diet that follows Canadian guidelines for a healthy eating better. In the Québec Longitudinal Study on Nutrition and Successful Aging, Commonly known as 'NuAge', Shatenstein et $a l .{ }^{(16)} \mathrm{did}$ not report any statistically significant association between CHEI and cognitive decline.

French National Nutrition and Health Programme (Programme National Nutrition Santé) Guideline Score. The PNNS-GS is composed of thirteen items with positive and negative scoring depending on the guideline. It includes twelve food guideline items and one physical activity item and ranges from 0 to 15. A higher PNNS-GS reflects good adherence to French food and physical activity guidelines for healthy living. Items are not dichotomous, but integrate a lower cut-off, intermediates values, and an upper boundary that allow some degree of moderation in rating the adherence to the guideline ${ }^{(17)}$. A study ${ }^{(59)}$ based on the SUpplémentation en VItamines et Minéraux Anti-oXydants (Supplementation with Antioxidant Vitamins and Minerals; SU.VI.MAX) cohort (45-60 years at baseline) highlighted that a higher PNNS-GS was associated with higher performance in several cognitive domains 13 years later. Indeed, statistically significant associations were observed with higher performance in episodic memory $(P<0.05)$, phonemic fluency $(P<0.05)$ and semantic verbal fluency $(P<0.05)$ for higher PNNS-GS, while no statistically significant association with working memory and mental flexibility was observed $^{(59)}$. However, since no baseline measurement of cognitive function was available, this study could not ascertain the link with cognitive decline.

Recommended and non-recommended Food Scores. The RFS was initially developed by Kant $e t a l .^{(18)}$ as a measurement of the variety of the diet according to 2005 Dietary Guidelines for Americans ${ }^{(18)}$. Other versions have been developed ${ }^{(60)}$ with a variation of the number of food items in the score but its computation remains based on assigning one point for a frequency of consumption above the recommendation, and 0 if not, with unweighted food items. Besides RFS, Kant et al. ${ }^{(18)}$ also developed a nonRFS score with one point for consumption above a cut-off frequency value for non-recommended highly processed and energy-dense foods (for example, processed meats, French fries and chips, sweets). A higher RFS means a higher diversity in the diet whereas a higher non-RFS reflects poor quality of the diet.

The RFS has been associated with cognitive decline in the Cache County Study (mean age range 73.8-75.6 depending on RFS quartile) ${ }^{(61)}$. A higher RFS was 
associated with higher mean 3MS scores (mean 3MS scores: first quartile of $\mathrm{RFS}=90 \cdot 4$, last quartile of $\mathrm{RFS}=91 \cdot 6$, $P<0.001)$ at baseline and lower cognitive decline when adjusted for many confounders. In the same study, the non-RFS was not associated with cognitive decline. To our knowledge, there are no publications using other versions of the RFS to assess relationships between variety of the diet and cognitive decline.

\section{General strengths and limitations of a priori methods}

As previously mentioned, a priori scores are easy to compute and reflect the adherence to specific dietary patterns or guidelines. In their review, Román-Viñas et al. ${ }^{(62)}$ reported the good validity and reproducibility of the HEI score, underlining the adequacy between this index and several nutrient intakes.

Even if a priori scores seem to be associated with cognitive outcomes in the aforementioned studies, these results should be interpreted with caution because of some methodological limitations. First, although the computation of the scores is intended to summarise previous scientific knowledge on separate food groups or on observed dietary patterns, subjective choices are sometimes necessary (for example, cut-off choices, foods gathering in items). A priori indexes are also based on the current knowledge on what a healthy diet is, for example fish was not considered in the first version of the $\mathrm{HEI}^{(15)}$ and $\mathrm{MeDi}$ score $^{(13)}$. HDI and MeDi scores are also trying to evaluate the effects of detrimental foods. Because of the limited knowledge about potentially detrimental effects of food on cognitive decline, current indexes do not deal with components that have been recently revealed as having damaging effects for many health problems such as trans-fatty acids ${ }^{(63)}$. These evolutions in the diet may have an effect on current ageing populations and should be considered in future studies. Moreover, using these indexes in further studies would help to test the efficacy of adherence to established guidelines (for example, HDI, HEI, CHEI, PNNS-GS) on brain ageing which is of major importance from a public health point of view. This is why researchers are developing new approaches to identify these changing dietary patterns ${ }^{(64)}$.

Second, these indexes do not capture all the complexity of the 'food matrix' which constitutes the rationale of studying the relationships between dietary patterns and health outcomes. Most of these dietary indexes were built to estimate adherence to a specific diet and did not account for the full diet. As reported by Waijers et al. ${ }^{(65)}$ it is not plausible that all components of the index have the same health impact, especially because they were not developed in regards with the impact on cognitive outcomes. Indeed, some of the scores included different components that were not reported in association with cognition (for example, HEI score has $\mathrm{Na}$ and total grain items that have never been found to be associated with cognitive decline).

Finally, few clues about how to weight the food groups or guidelines have been proposed. Only computing of the PNNS-GS allows a range of values for the items but their validation is missing.

\section{Perspectives with a priori scores in relationship with cognitive decline}

Researchers have tried several ways to improve the indexes before testing associations with cognitive decline: updating scores with new guidelines (for example, 2005 version of the HEI); modifying them according to new hypotheses (for example, later inclusion of fish consumption in the HEI and MeDi) or population specificities (for example, choice of a population-based cut-off value for alcohol consumption item to compute the MeDi score in the French population ${ }^{(50)}$ ). These modified scores remain poorly associated with cognition.

Another perspective is the development of RCT testing the impact of a specific dietary programme on the evolution of cognitive decline. To date, only one dietary programme was evaluated in an RCT with the investigation of the evolution of cognitive function as an outcome: the Dietary Approaches to Stop Hypertension (DASH). The DASH diet was proposed in 1999 to prevent hypertension $^{(66)}$. This diet is supposed to provide recommended amounts of essential nutrients such as fibres, K, Ca and $\mathrm{Mg}$ and limited intakes of salt and saturated fats. This diet is composed of grain and grain products, fruits, vegetables, low-fat or non-fat dairy foods, lean meats, fish, poultry, nuts, seeds and legumes, and a limited consumption of fats and refined sugar-rich foods. Smith et al. ${ }^{(67)}$ found in a very specific population of overweight individuals (middle-aged subjects) that the DASH diet combined with a behavioural weight-management programme improved both function memory learning $(P=0.008)$ and psychomotor speed $(P=0.023)$ after a 4-month intervention, compared with controls following their usual diet. The dietary programme alone enhanced only psychomotor speed $(P=0 \cdot 036)$. The authors admitted that this intervention only lasted 4 months; thus, both the extent to which these improvements could be maintained and the clinical significance of their results is unknown.

A 4-week RCT compared the effects of two different diets on insulin and lipid metabolism, cerebrospinal fluid markers of $\mathrm{AD}$, and cognition in healthy subjects and subjects with amnestic MCI, aged on average 68 years $^{(68)}$. The two diets were the high-saturated fat/high-glycaemic index (HIGH) diet ( $45 \%$ fat with 25\% saturated fat, 35-40\% carbohydrates with glycaemic index $>70$ and 15-20\% protein) compared with a low-saturated fat/low-glycaemic index (LOW) diet (25\% fat with 7\% saturated fat, 55-60\% carbohydrates with glycaemic index $<55$ and 15-20\% protein). This short modification of the diet succeeded in 
highlighting that delayed visual memory, a hallmark cognitive deficit in amnestic MCI and $\mathrm{AD}$, was improved with the LOW diet.

Further RCT and longitudinal studies with longer followup with the MeDi and other previously mentioned diet scores such as the HDI, HEI, CHEI or PNNS-GS should help to reach a higher level of evidence in their association with cognitive decline in older individuals. However, such RCT involve long-term changes in the diet of older individuals which is complicated, expensive to undertake and maybe not be feasible. More convincing results from observational studies identifying specific dietary patterns associated with lower cognitive decline are needed to encourage the implementation of these RCT.

\section{Cognitive function and a posteriori methods for dietary pattern analysis}

A posteriori dietary patterns also called empirically derived or exploratory dietary patterns have the main advantage of being data-driven, and, thus, not depending on previous hypotheses and being limited by current knowledge in nutrition. Few studies have examined the link between these patterns and cognitive decline. Further information about the studies quoted in this section is listed in Table 2 .

\section{Principal components analysis}

PCA is a dimension-reduction technique widely used in factor analysis applied in nutritional epidemiology. Highly correlated food variables are summarised by principal components, uncorrelated linear combinations of weighted observed variables (for example, eigenvectors) derived under the constraint of explaining a maximal amount of the variance (for example, eigenvalue) in the data. This choice of factor analysis is based on the selection of the principal components according to their eigenvalues, but also the interpretability of the factors and the percentage of variance explained by those factors. The factor loading represents the correlation coefficient between the food variable and a principal component. A principal component score for each pattern is then calculated for a given subject by summing his/her intakes of foods weighted by the coefficient for this food in the factor. An orthogonal rotation (varimax is the most common one) is often used to achieve a simpler structure, to help the interpretability by discriminating factor loadings ${ }^{(69-71)}$. In the case of food patterns, when a factor is heavily loaded with foods or nutrients, it means that these components of the diet are significantly qualifying it. For a given individual, the highest a factor pattern score is, the closer the diet of this individual matches this pattern.

In a cross-sectional analysis from the Whitehall II study (participants about 60 years of age), two dietary patterns were identified and further related to cognitive performances: a 'whole food' pattern characterised by higher factor loadings for vegetables and fruits and the 'processed food' pattern characterised by higher factor loadings for high-fat and processed foods. The highest tertile of the processed pattern was associated with higher risks of cognitive impairment in vocabulary (OR 1.63; 95\% CI 1.25, 2.13) and phonemic fluency (OR 1.34; $95 \%$ CI 1.04, 1.74). In contrast, protective associations were observed between the 'whole food' pattern and vocabulary (OR $0.75 ; 95 \%$ CI $0.60,0.92)$ and semantic fluency (OR $0.72 ; 95 \%$ CI $0.59,0.88)^{(72)}$. To the best of our knowledge, this is the only study using PCA in the field of cognitive impairment and no studies have been conducted in older individuals. Moreover, the findings are limited by the cross-sectional design.

\section{Clustering methods}

Cluster analysis is a classification technique enabling the grouping of subjects into homogeneous non-overlapping groups, based on their similarities in a particular set of variables ${ }^{(73,74)}$. In the nutrition context, clustering results in grouping subjects in a similar pattern of mean food intake. The $k$-means and Ward's clustering are two extensively used cluster analysis methods in nutritional epidemiology ${ }^{(74)}$. Clustering methods allow dividing subjects into clusters that minimise the sum of squares distances from each subject to the cluster mean. In dietary pattern approaches, each cluster can then be qualified as a food pattern. The main limitation of the $k$-means cluster analysis is that it involves the a priori definition of the number of clusters. Another limitation is that it is very sensitive to small changes in the sample, potentially questioning its relevance, although methods have been developed to test the reliability ${ }^{(74-80)}$

To overcome this limitation, in the 3C study, Samieri et $a l .{ }^{(75)}$ applied a mixed clustering method that uses both $k$-means and Ward's methods to increase the stability of the groups. The first step of this hybrid clustering is a $k$-means clustering procedure that groups subjects into exclusive clusters based on Euclidian distance of observations from the cluster centroid in an iterative process. In a second step, the Ward's hierarchical clustering procedure is performed on stable groups. This process allows constructing a tree that can be cut to a level corresponding to validated criteria and to obtain clusters. A third consolidation step is finally performed involving a last $k$-means partition. Overall, five clusters or dietary patterns were obtained: the first three - 'small eaters', 'biscuits and snacking' and a 'healthy' pattern - were similar in men and women. Two other patterns were more sex specific: a 'charcuterie meat and alcohol' pattern in men, $v$. a 'charcuterie and starch foods' pattern in women; a 'pasta eaters' pattern in men $v$. a 'pizza and sandwich' pattern in women. In both sexes, mean MMSE score was higher for individuals in the 'healthy' pattern (for men: mean MMSE $=27 \cdot 8, P=0.04$; and for women: mean MMSE $=27.6, \quad P=0.004$ in multivariate models). MMSE was lower in the 'biscuits and snacking' 


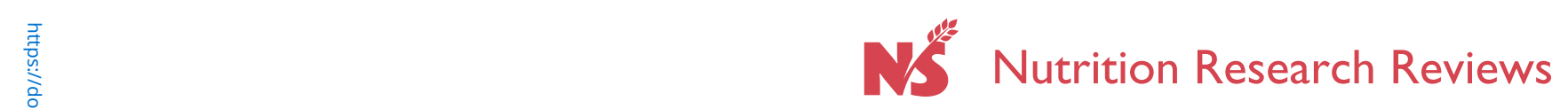

Table 2. Main studies using a posteriori methods in the context of cognitive decline and Alzheimer's disease (AD)

\begin{tabular}{|c|c|c|c|c|c|c|c|}
\hline Reference, study country & Design & $\begin{array}{l}\text { Sample } \\
\text { size }\end{array}$ & $\begin{array}{l}\text { Mean age of the } \\
\text { sample at baseline }\end{array}$ & $\begin{array}{l}\text { A posteriori dietary } \\
\text { pattern used }\end{array}$ & $\begin{array}{l}\text { Dietary intake } \\
\text { assessment } \\
\text { method }\end{array}$ & $\begin{array}{l}\text { Cognitive } \\
\text { outcome, } \\
\text { measurement }\end{array}$ & Main results \\
\hline $\begin{array}{l}\text { Samieri et al. }(2008)^{(75)} \text {, } \\
\text { 3C, France }\end{array}$ & Cross-sectional & 1724 & $\begin{array}{l}76.5-78.5 \text { years, } \\
\text { depending on } \\
\text { clusters }\end{array}$ & Cluster & $\mathrm{FFQ}$ & MMSE & $\begin{array}{l}\text { Mean MMSE score higher for individuals in the } \\
\text { 'healthy' pattern, and lower in the 'biscuits and } \\
\text { snacking' cluster (for men } P=0.06 \text { and for } \\
\text { women } P=0.002 \text { ) } \\
\text { Fewer errors for MMSE test for individuals in the } \\
\text { 'healthy' cluster: statistically significant associ- } \\
\text { ation reported in multivariate regression in both } \\
\text { groups of sexes (for men } P=0.04 \text { and for } \\
\text { women } P=0.004 \text { ) }\end{array}$ \\
\hline \multirow[t]{2}{*}{$\begin{array}{l}\text { Akbaraly et al. }(2009)^{(72)} \\
\text { Whitehall II study, England }\end{array}$} & Cross-sectional & 4693 & $\begin{array}{l}60 \cdot 7-61 \cdot 3 \text { years } \\
\text { 'whole food' pattern }\end{array}$ & $\begin{array}{l}\text { Principal } \\
\text { components } \\
\text { analysis }\end{array}$ & $\begin{array}{l}\text { Semi-quantitative } \\
\quad \text { FFQ }\end{array}$ & $\begin{array}{l}\text { Five cognitive domains } \\
\text { tested: memory, reason- } \\
\text { ing, vocabulary test, pho- } \\
\text { nemic fluency, semantic } \\
\text { fluency }\end{array}$ & $\begin{array}{l}\text { The 'whole food' pattern was significantly associ- } \\
\text { ated with lower risks of vocabulary (3rd tertile } \\
\text { of the pattern } v \text {. 1st tertile: OR } 0.78 ; 95 \% \\
\mathrm{Cl} 0.63,0.92 \text { ) and semantic fluency deficits } \\
\text { (3rd tertile of the pattern } v \text {. 1st tertile: OR } 0.72 \text {; } \\
95 \% \mathrm{Cl} 0.59,0.88 \text { ) in fully adjusted models }\end{array}$ \\
\hline & & & $\begin{array}{l}60 \cdot 9-61 \cdot 2 \text { years } \\
\text { 'processed food' } \\
\text { pattern }\end{array}$ & & & & $\begin{array}{l}\text { The 'processed food' pattern was significantly } \\
\text { associated with higher risks of vocabulary } \\
\text { (3rd tertile of the pattern } v \text {. 1st tertile: OR } 1.63 \text {; } \\
95 \% \mathrm{Cl} 1.25,2.13 \text { ) and phonemic fluency } \\
\text { deficits (3rd tertile of the pattern } v \text {. 1st tertile: } \\
\text { OR } 1.34 ; 95 \% \text { Cl } 1.04,1.74 \text { ) in fully adjusted } \\
\text { models }\end{array}$ \\
\hline $\begin{array}{l}\text { Gu et al. }(2010)^{(92) y} \text {, } \\
\text { WHICAP, USA }\end{array}$ & $\begin{array}{l}\text { Cohort (longitudinal) } \\
\text { Follow up: } 4 \text { years }\end{array}$ & 2148 & 77.2 years & $\begin{array}{l}\text { Reduced rank } \\
\text { regression }\end{array}$ & $\begin{array}{l}\text { Semi-quantitative } \\
\text { FFQ }\end{array}$ & $\begin{array}{l}\text { Incident dementia } \\
\text { (DSM-III-R, } \\
\text { NINCDS-ADRDA) }\end{array}$ & $\begin{array}{l}\text { One of the dietary patterns (DP2) was signifi- } \\
\text { cantly associated with lower AD risk (3rd tertile } \\
v \text {. 1st: HR } 0.62 ; 95 \% \mathrm{Cl} 0.43,0.89 \text { ) in fully } \\
\text { adjusted models }\end{array}$ \\
\hline
\end{tabular}

3C, Three-City; MMSE, Mini-Mental State Examination; WHICAP, Washington Heights-Inwood Columbia Aging project; DSM-III-R, Diagnostic and Statistical Manual of Mental Disorders, third edition revised; NINCDS-ADRDA, National Institute of Neurological and Communicative Disorders and Stroke and the Alzheimer's Disease and Related Disorders Association; HR, hazard ratio. 
cluster for women (mean MMSE $=26 \cdot 6, P=0.03$ in univariate analysis) but this association became non-significant in multivariate regression stratified by $\operatorname{sex}^{(75)}$. To our knowledge, there is no other example of implementation of this method in the field of nutrition and cognition.

\section{Reduced rank regression}

Exploratory methods such as PCA and cluster analysis do not use prior knowledge of the diet-disease relationship, thus ignoring key nutrients that are likely to be implied in the physiopathology. RRR, a semi-exploratory statistical method close to PCA, was recently applied to nutritional epidemiology ${ }^{(81)}$ to derive patterns of food intake that focus on the variability of these key nutrients.

RRR determines linear functions of a first set of variables called predictors (typically, food groups) by maximising the explained variation of a set of response variables (nutrients, or biomarkers) ${ }^{(81)}$. It starts from a linear function of responses called response score (obtained by PCA), which is projected onto the space of predictors to produce a factor score, a linear function of predictors. As in PCA analysis, a score for each pattern is then calculated for a given subject. The resulting factor scores can be interpreted as dietary patterns and are further related to health outcomes.

RRR has already allowed the identification of patterns associated with diabetes mellitus ${ }^{(82)}$ and other chronic diseases $^{(83-91)}$. To our knowledge, only one study from the WHICAP cohort used RRR in the context of cognitive decline. The authors identified seven different empirically derived dietary patterns with this technique. One of them was significantly associated with a lower risk of $\mathrm{AD}$ (hazard ratio $0.62 ; 95 \%$ CI $0.43,0.89$ for the highest tertile of dietary pattern score compared with the lowest one) ${ }^{(92)}$. The pattern reflected higher intakes of $n-3$ and n-6 PUFA, vitamin $\mathrm{E}$ and folate with a higher consumption of salad dressing, nuts, fish, tomatoes, poultry, cruciferous vegetables, fruits and dark green leafy vegetables and lower intakes of high-fat dairy products, red meat, organ meat and butter.

\section{General strengths and limitations of a posteriori dietary patterns}

The main advantage of the a posteriori methods is that they allow taking into account complex correlations of the 'food matrix'. Another interesting aspect of these methods is that contrary to a priori indexes, they are not hypothesis-driven choices. Both cluster analysis and PCA in a same study sample can identify dietary patterns which are very similar in terms of consumption of nutrients, thus reflecting a good internal validity, as discussed by Román-Viñas et al. ${ }^{(62)}$ but to our knowledge there are no such comparisons in the context of cognitive decline.

A first limitation is that empirically derived patterns are supposed to reflect food behaviour as close as possible to reality in the study sample. This questions their reproducibility: even when performing these analyses with a same methodology in different epidemiological studies, the final structure of identified patterns depends on the sample and limits comparisons between studies. Moreover, even if it is a general limitation of many analyses in nutritional epidemiology, it has been demonstrated that these methods, especially PCA, are sensitive to the type of collected nutritional information. In a Greek study, the authors derived patterns from both FFQ and a $3 \mathrm{~d}$ diary $^{(93)}$. For instance, four major components derived using PCA from the FFQ explained $35 \%$ of the diet variation whereas $29 \%$ of the diet variation was explained by four components derived from the $3 \mathrm{~d}$ diary.

Another limitation of the a posteriori patterns is that they are based on underlying complex statistical analyses that require good skills in multidimensional methods. The investigators must be able to select a limited number of components that summarise the best underlying food patterns, increasing subjectivity. These exploratory analyses are also influenced by the authors' subjective choices to decide how many foods or nutrients to enter into the PCA or creating food groups to gather marginal consumption of some foods.

Finally, authors choose specific labels for the patterns based on their own interpretation. This is why it is important to know the description of food consumption characterising the patterns. For example, exploratory analyses in two different populations may allow the identification of a 'healthy' labelled pattern that may yield distinct food consumptions in each study as highlighted by Slattery et al. ${ }^{(94)}$, thus questioning their external validity. In particular, the amount and quality of food labelled as 'healthy diet' are influenced by culture and geography. For example, a healthy diet in the $3 \mathrm{C}$ study in France may be different from the 'whole food' pattern of the Whitehall II Study in England but both have a protective association against cognitive decline. It is not possible to assess their external validity because there is no information about the mean amount of food consumption in these two populations. Detailed information about the diet is needed to validate these patterns. It is obvious that there are not enough studies with empirically derived patterns to provide evidence of their association with cognitive decline but the first results are promising and further investigations are required.

Perspectives with a posteriori approaches in relationship with cognitive decline

There is an element of subjectivity in the interpretation of $a$ posteriori patterns. Further analysis to assess their validity is required. In the context of cognitive decline, little information is given about nutrient profiles or description of the consumption of each food group in the derived patterns. Another perspective uses several exploratory approaches in the same sample to derive patterns allowing 
comparisons and testing internal validity. For instance, Smith et $a l{ }^{\left({ }^{(7)}\right.}$ in a UK cohort of children used both cluster analysis and PCA to identify dietary patterns. They observed similarities between the patterns derived by the two methods in the consumption of food but also in sociodemographic characteristics while no association with health outcomes was reported. To our knowledge, using several exploratory analyses to derive food patterns and investigation of their association with cognitive decline has never been performed.

As PCA and RRR are mainly exploratory analyses, subjectivity remains in the choice of the parameters such as rotation method or number of components finally selected. Further research in the context of cognitive decline, dementia and $\mathrm{AD}$ is needed to assess reproducibility of results.

General limitations in the investigation of the link between food and cognitive function in older individuals

\section{Diversity of cognitive outcomes}

Various cognitive outcomes can be considered when studying the relationship between cognitive function and dietary patterns in older individuals. For example, in studies focusing on a priori scores, the outcomes considered were global cognitive function, specific cognitive domains, incident cases of dementia and MCI cases and their conversion to dementia. Moreover, a similar outcome can be evaluated with different psychometric tests: Féart et al. ${ }^{(50)}$ used the MMSE to assess global cognitive function but also other neuropsychological tests specific of cognitive domains in relationship with the MeDi, whereas Tangney et al. ${ }^{(52)}$ averaged MMSE and Symbol Digit Modalities Test $z$-scores. In a posteriori analyses three different outcomes were considered: global cognitive function (MMSE), isolated cognitive domains and incident cases of $\mathrm{AD}$, adding complexity in both interpretation and comparisons between studies due to previously discussed methodological issues combined with this diversity of cognitive outcomes.

\section{Strengths and limitations of dietary assessment methods}

Most studies focusing on dietary patterns and cognitive outcomes used FFQ. These tools reflect food consumption patterns over time and neglect capturing rarely consumed foods. Most FFQ used in the studies reported in Tables 1 and 2 were quantitative or semi-quantitative, allowing good estimation of portion sizes, whereas the studies of Féart et al. ${ }^{(50)}$ and Samieri et al. ${ }^{(75)}$ did not allow this estimation thus limiting comparability of consumption within subgroups of subjects.

In the context of impaired cognitive function in the elderly, the accuracy of nutrient intake estimation by a FFQ has been assessed by Bowman et al. ${ }^{(95)}$ in a sample of thirty-eight subjects (mean age 74 years). They compared the reliability and validity of FFQ using correlations between nutrients estimated by their questionnaire and plasma nutrients in individuals with and without MCI. Accounting for their small sample size, they concluded that memory state could influence the validity of FFQ. After stratifying by cognitive diagnosis, in the subsample of individuals with MCI there were more negative correlation coefficients, whereas there were more positive correlations between FFQ and plasma nutrients in noncognitively impaired older individuals.

\section{Importance of midlife exposure}

Studies of associations between cognitive performances and midlife exposure have indicated that vascular events such as hypertension, diabetes mellitus and smoking could increase the risk of dementia in later life ${ }^{(96)}$. Midlife obesity has also been linked with a higher risk of cognitive decline and dementia ${ }^{(97,98)}$. To date, only one longitudinal study, the Cardiovascular risk factors, Aging and Dementia (CAIDE), reported results about protective effects of a 'healthy diet' in midlife on late-life risk of dementia and $\mathrm{AD}^{(99)}$. Reliable retrospective assessment of dietary intakes is very difficult and very few cohort studies started in midlife, thus the studies reported in the present review rarely took into account the life course diet of subjects.

\section{Publication bias}

All published studies reported at least one statistically significant association between dietary patterns and cognitive function but concerned various cognitive outcomes. By contrast, only a few studies reported a lack of association between cognitive outcomes and a priori patterns, regarding, respectively, the MeDi and global cognitive decline ${ }^{(49,53)}$ or dementia ${ }^{(50)}$, and the $\mathrm{HEI}^{(52)}$ or $\mathrm{CHEI}^{(16)}$ and global cognitive decline. To date no study reported the absence of associations between cognitive function or $\mathrm{AD}$ and a posteriori-derived dietary patterns analysis. Thus, it is likely that negative results were not published, supporting a potential publication bias.

\section{Conclusion}

Dietary patterns are a promising strategy to investigate the link between food and cognitive decline. A priori methods showed that the MeDi score, the PNNS-GS, the RFS and the DASH diet were associated with cognitive outcomes such as less cognitive impairment, cognitive decline or lower risk for $\mathrm{AD}$ (the latter only for MeDi score), but the level of evidence for these indexes has to be strengthened in particular by investigating new cohort studies in other countries. Other guideline-based food scores do not seem to be consistently associated with cognitive decline. 
Exploratory analyses also allowed the identification of patterns associated with cognitive decline.

Taken altogether, these data suggest that diets rich in fruits, vegetables, other plant-derived products, sea products rich in $n$-3 PUFA and with lower intakes of meat, highly saturated fat and added refined sugar could be protective against cognitive decline but with some remaining inconsistency due in part to methodological limitations. Challenges in the investigation of the relationship between dietary patterns and cognitive decline are presented in Fig. 1.

To achieve a higher level of evidence, further internal validation of patterns is needed. For example, describing these dietary patterns in relation to biomarkers would add considerable support to their interpretation.
Moreover, other lifestyle factors such as physical activity or anthropometric characteristics that could induce residual confounding in the relationship between dietary patterns and cognitive decline should be carefully controlled for.

Harmonisation of the methods to obtain both a priori and a posteriori dietary patterns would be useful to better understand the relationship between these dietary patterns and cognitive decline. New strategies such as conducting dietary pattern analysis with multiple analytic methods to compare dietary patterns and assess their validity ${ }^{(100,101)}$ may be interesting in the context of cognitive decline.

Besides dietary pattern studies, single nutrient approaches should focus on enhancing the comprehension of mechanisms underlying their potential effect against cognitive decline. For example, RCT with longer follow-up,

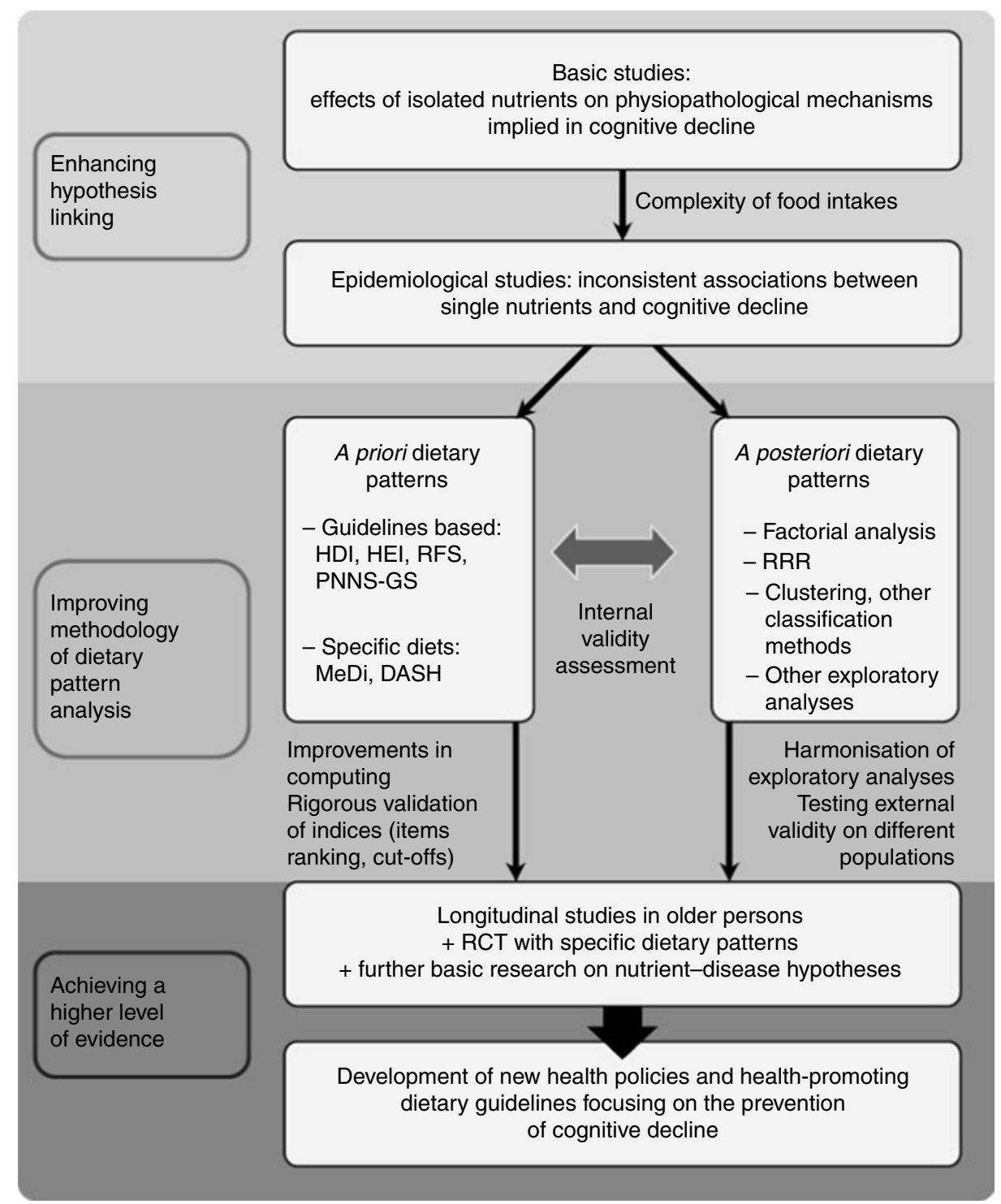

Fig. 1. Challenges in the investigation of the relationship between dietary patterns and cognitive decline. HDI, Healthy Diet Indicator; HEI, Healthy Eating Index; RFS, Recommended Food Score; PNNS-GS, French National Nutrition and Health Programme (Programme National Nutrition Santé) Guideline Score; MeDi, Mediterranean diet; DASH, Dietary Approaches to Stop Hypertension; RRR, reduced rank regression; RCT, randomised controlled trial. 
testing benefits of dietary supplements that mimic the composition of an optimal diet, could also help in the understanding of the specific role of nutrients in the context of neurodegenerative processes and cognitive decline. However, if we make the plausible assumption that healthy dietary patterns must be started early and sustained late in life to observe benefits on cognition, such RCT may be impossible to implement. Thus, more evidence should come from both experimental and epidemiological studies investigating the effect of combinations of nutrients. In the absence of convincing information about protective effects of single foods or nutrients provided by current observational studies, development of longitudinal cohorts focusing on dietary patterns with substantial follow-up would strengthen hypotheses linking food and cognitive decline in older individuals. In this regard, a higher level of evidence about protective effects of specific food patterns, coming from both a priori and a posteriori methods, may provide valuable knowledge to support the development of nutritional policies and programmes to prevent cognitive decline and $\mathrm{AD}$.

\section{Acknowledgements}

This research received no specific grant from any funding agency in the public, commercial or not-for-profit sectors. D. L. is supported by a scientist award from the Fonds de la recherche du Québec - Santé. P. B.-G. served on a scientific advisory board for Caisse Nationale pour la Solidarite et l'Autonomie (CNSA); has received funding for travel and speaker honoraria from Lesieur, Bausch \& Lomb, Aprifel, Danone Institute, Canadian Association of Gerontology, and the Jean Mayer Human Nutrition Research Center on Aging, Tufts University; has received consultancy fees from Vifor Pharma; and receives research support from Lesieur, Danone, Agence Nationale de la Recherche, Conseil Régional d'Aquitaine, Institut Carnot LISA and Groupe Lipides et Nutrition.

B. A. made the review of the literature and drafted the manuscript. D. L. and P. B.-G. contributed to the drafting of the manuscript and supervised B. A. as his PhD cosupervisors. C. S., C. F. and M.-A. J. contributed to the literature review and provided significant advice. All authors made a critical review of the draft.

The authors do not report any conflict of interest.

\section{References}

1. Daviglus ML, Bell CC, Berrettini W, et al. (2010) National Institutes of Health State-of-the-Science Conference statement: preventing Alzheimer disease and cognitive decline. Ann Intern Med 153, 176-181.

2. Daviglus ML, Plassman BL, Pirzada A, et al. (2011) Risk factors and preventive interventions for Alzheimer disease: state of the science. Arch Neurol 68, 1185-1190.

3. Plassman BL, Williams JW Jr, Burke JR, et al. (2010) Systematic review: factors associated with risk for and possible prevention of cognitive decline in later life. Ann Intern Med 153, 182-193.

4. Filley CM \& Anderson CA (2011) Dementia: five new things. Neurology 76, Suppl. 2, S26-S30.

5. Wald DS, Kasturiratne A \& Simmonds M (2010) Effect of folic acid, with or without other B vitamins, on cognitive decline: meta-analysis of randomized trials. $\mathrm{Am} \mathrm{J} \mathrm{Med}$ $\mathbf{1 2 3}, 522-527$

6. van de Rest O, Geleijnse JM, Kok FJ, et al. (2008) Effect of fish oil on cognitive performance in older subjects: a randomized, controlled trial. Neurology 71, 430-438.

7. Dangour AD, Allen E, Elbourne D, et al. (2010) Effect of $2-y=3$ long-chain polyunsaturated fatty acid supplementation on cognitive function in older people: a randomized, double-blind, controlled trial. Am J Clin Nutr 91, 1725-1732.

8. Jia X, McNeill G \& Avenell A (2008) Does taking vitamin, mineral and fatty acid supplements prevent cognitive decline? A systematic review of randomized controlled trials. J Hum Nutr Diet 21, 317-336.

9. Gu Y \& Scarmeas N (2011) Dietary patterns in Alzheimer's disease and cognitive aging. Curr Alzheimer Res 8, $510-519$

10. Jacobs DR, Gross MD \& Tapsell LC (2009) Food synergy: an operational concept for understanding nutrition. Am J Clin Nutr 89, 1543S-1548S.

11. Jacobs DR \& Steffen LM (2003) Nutrients, foods, and dietary patterns as exposures in research: a framework for food synergy. Am J Clin Nutr 78, 508S-513S.

12. Jacobs DR \& Tapsell LC (2007) Food, not nutrients, is the fundamental unit in nutrition. Nutr Rev 65, 439-450.

13. Trichopoulou A, Kouris-Blazos A, Wahlqvist ML, et al. (1995) Diet and overall survival in elderly people. BMJ 311, 1457-1460.

14. Huijbregts P, Feskens E, Räsänen L, et al. (1997) Dietary pattern and 20 year mortality in elderly men in Finland, Italy, and The Netherlands: longitudinal cohort study. BMJ 315, $13-17$.

15. Kennedy ET, Ohls J, Carlson S, et al. (1995) The Healthy Eating Index: design and applications. J Am Diet Assoc 95, 1103-1108.

16. Shatenstein B, Ferland G, Belleville S, et al. (2012) Diet quality and cognition among older adults from the NuAge study. Exp Gerontol 47, 353-360.

17. Estaquio C, Kesse-Guyot E, Deschamps V, et al. (2009) Adherence to the French Programme National Nutrition Santé Guideline Score is associated with better nutrient intake and nutritional status. J Am Diet Assoc 109, 1031-1041.

18. Kant AK, Schatzkin A, Graubard BI, et al. (2000) A prospective study of diet quality and mortality in women. JAMA 283, 2109-2115.

19. Folstein MF, Folstein SE \& McHugh PR (1975) "Mini-mental state". A practical method for grading the cognitive state of patients for the clinician. J Psychiatr Res 12, 189-198.

20. Teng EL \& Chui HC (1987) The Modified Mini-Mental State (3MS) examination. J Clin Psychiatry 48, 314-318.

21. Ballard C, Gauthier S, Corbett A, et al. (2011) Alzheimer's disease. Lancet 377, 1019-1031.

22. Querfurth HW \& LaFerla FM (2010) Alzheimer's disease. $N$ Engl J Med 362, 329-344.

23. Mudher A \& Lovestone S (2002) Alzheimer's disease - do tauists and baptists finally shake hands? Trends Neurosci 25, 22-26.

24. Lim GP, Calon F, Morihara T, et al. (2005) A diet enriched with the omega-3 fatty acid docosahexaenoic acid reduces amyloid burden in an aged Alzheimer mouse model. J Neurosci 25, 3032-3040. 
25. Green KN, Martinez-Coria H, Khashwji H, et al. (2007) Dietary docosahexaenoic acid and docosapentaenoic acid ameliorate amyloid- $\beta$ and tau pathology via a mechanism involving presenilin 1 levels. J Neurosci 27, 4385-4395.

26. Florent S, Malaplate-Armand C, Youssef I, et al. (2006) Docosahexaenoic acid prevents neuronal apoptosis induced by soluble amyloid- $\beta$ oligomers. I Neurochem 96, 385-395.

27. Boudrault C, Bazinet RP \& Ma DWL (2009) Experimental models and mechanisms underlying the protective effects of $n-3$ polyunsaturated fatty acids in Alzheimer's disease. J Nutr Biochem 20, 1-10.

28. Lukiw WJ, Cui J-G, Marcheselli VL, et al. (2005) A role for docosahexaenoic acid-derived neuroprotectin D1 in neural cell survival and Alzheimer disease. J Clin Invest 115, 2774-2783.

29. Freund-Levi Y, Basun H, Cederholm T, et al. (2008) Omega3 supplementation in mild to moderate Alzheimer's disease: effects on neuropsychiatric symptoms. Int J Geriatr Psychiatry 23, 161-169.

30. Freund-Levi Y, Hjorth E, Lindberg C, et al. (2009) Effects of omega-3 fatty acids on inflammatory markers in cerebrospinal fluid and plasma in Alzheimer's disease: the OmegAD study. Dement Geriatr Cogn Disord 27, 481-490.

31. Innis SM (2007) Dietary (n-3) fatty acids and brain development. J Nutr 137, 855-859.

32. Calder PC (2012) Mechanisms of action of (n-3) fatty acids. J Nutr 142, 592S-599S.

33. Devore EE, Kang JH, Stampfer MJ, et al. (2010) Total antioxidant capacity of diet in relation to cognitive function and decline. Am J Clin Nutr 92, 1157-1164.

34. Young IS \& Woodside JV (2001) Antioxidants in health and disease. J Clin Pathol 54, 176-186.

35. Gillette-Guyonnet S, Andrieu S, Dantoine T, et al. (2009) Commentary on "A roadmap for the prevention of dementia II. Leon Thal Symposium 2008." The Multidomain Alzheimer Preventive Trial (MAPT): a new approach to the prevention of Alzheimer's disease. Alzheimers Dement $\mathbf{5}$, $114-121$.

36. Annweiler C, Schott AM, Rolland Y, et al. (2010) Dietary intake of vitamin $\mathrm{D}$ and cognition in older women: a large population-based study. Neurology 75, 1810-1816.

37. Cunnane SC, Plourde M, Pifferi F, et al. (2009) Fish, docosahexaenoic acid and Alzheimer's disease. Prog Lipid Res $\mathbf{4 8}$, $239-256$.

38. Mazereeuw G, Lanctôt KL, Chau SA, et al. (2012) Effects of omega-3 fatty acids on cognitive performance: a meta-analysis. Neurobiol Aging 33, 1482.e17-1482.e29.

39. Barberger-Gateau P, Raffaitin C, Letenneur L, et al. (2007) Dietary patterns and risk of dementia: the Three-City cohort study. Neurology 69, 1921-1930.

40. Willett WC, Sacks F, Trichopoulou A, et al. (1995) Mediterranean diet pyramid: a cultural model for healthy eating. Am J Clin Nutr 61, 1402S-1406S.

41. Sofi F, Abbate R, Gensini GF, et al. (2010) Accruing evidence on benefits of adherence to the Mediterranean diet on health: an updated systematic review and meta-analysis. Am J Clin Nutr 92, 1189-1196.

42. Trichopoulou A, Costacou T, Bamia C, et al. (2003) Adherence to a Mediterranean diet and survival in a Greek population. $N$ Engl J Med 348, 2599-2608.

43. Sofi F, Macchi C, Abbate R, et al. (2010) Effectiveness of the Mediterranean diet: can it help delay or prevent Alzheimer's disease? J Alzheimers Dis 20, 795-801.

44. Solfrizzi V, Frisardi V, Seripa D, et al. (2011) Mediterranean diet in predementia and dementia syndromes. Curr Alzheimer Res $\mathbf{8}, 520-542$.
45. Trichopoulou A, Orfanos P, Norat T, et al. (2005) Modified Mediterranean diet and survival: EPIC-elderly prospective cohort study. BMJ 330, 991.

46. Scarmeas N, Luchsinger JA, Schupf N, et al. (2009) Physical activity, diet, and risk of Alzheimer disease. JAMA $\mathbf{3 0 2}$ 627-637.

47. Scarmeas N, Stern Y, Mayeux R, et al. (2006) Mediterranean diet, Alzheimer disease, and vascular mediation. Arch Neurol 63, 1709-1717.

48. Scarmeas N, Stern Y, Mayeux R, et al. (2009) Mediterranean diet and mild cognitive impairment. Arch Neurol $\mathbf{6 6}$ 216-225.

49. Psaltopoulou T, Kyrozis A, Stathopoulos P, et al. (2008) Diet, physical activity and cognitive impairment among elders: the EPIC-Greece cohort (European Prospective Investigation into Cancer and Nutrition). Public Health Nutr 11, 1054-1062.

50. Féart C, Samieri C, Rondeau V, et al. (2009) Adherence to a Mediterranean diet, cognitive decline, and risk of dementia. JAMA 302, 638-648.

51. Féart C, Samieri C \& Barberger-Gateau P (2010) Mediterranean diet and cognitive function in older adults. Curr Opin Clin Nutr Metab Care 13, 14-18.

52. Tangney CC, Kwasny MJ, Li H, et al. (2011) Adherence to a Mediterranean-type dietary pattern and cognitive decline in a community population. Am J Clin Nutr 93, 601-607.

53. Cherbuin N \& Anstey KJ (2011) The Mediterranean diet is not related to cognitive change in a large prospective investigation: the PATH through life study. Am J Geriatr Psychiatry (epublication ahead of print version 20 September 2011).

54. Barnes DE (2011) The Mediterranean diet: good for the heart=good for the brain? Ann Neurol 69, 226-228.

55. Scarmeas N, Stern Y, Tang M-X, et al. (2006) Mediterranean diet and risk for Alzheimer's disease. Ann Neurol 59 , 912-921.

56. Huijbregts PP, Feskens EJ, Räsänen L, et al. (1998) Dietary patterns and cognitive function in elderly men in Finland, Italy and The Netherlands. Eur J Clin Nutr 52, 826-831.

57. Corrêa Leite ML, Nicolosi A, Cristina S, et al. (2001) Nutrition and cognitive deficit in the elderly: a population study. Eur J Clin Nutr 55, 1053-1058.

58. Shatenstein B, Nadon S, Godin C, et al. (2005) Diet quality of Montreal-area adults needs improvement: estimates from a self-administered food frequency questionnaire furnishing a dietary indicator score. J Am Diet Assoc 105, 1251-1260.

59. Kesse-Guyot E, Amieva H, Castetbon K, et al. (2011) Adherence to nutritional recommendations and subsequent cognitive performance: findings from the prospective Supplementation with Antioxidant Vitamins and Minerals 2 (SU.VI.MAX 2) study. Am J Clin Nutr 93, 200-210.

60. Kaluza J, Hakansson N, Brzozowska A, et al. (2007) Diet quality and mortality: a population-based prospective study of men. Eur J Clin Nutr 63, 451-457.

61. Wengreen HJ, Neilson C, Munger R, et al. (2009) Diet quality is associated with better cognitive test performance among aging men and women. J Nutr 139, 1944-1949.

62. Román-Viñas B, Ribas Barba L, Ngo J, et al. (2009) Validity of dietary patterns to assess nutrient intake adequacy. BrJ Nutr 101, S12-S20.

63. Remig V, Franklin B, Margolis S, et al. (2010) Trans fats in America: a review of their use, consumption, health implications, and regulation. J Am Diet Assoc 110, 585-592.

64. Monteiro CA, Levy RB, Claro RM, et al. (2011) Increasing consumption of ultra-processed foods and likely impact 
on human health: evidence from Brazil. Public Health Nutr 14, 5-13.

65. Waijers PMCM, Feskens EJM \& Ocké MC (2007) A critical review of predefined diet quality scores. Br J Nutr 97, 219-231.

66. Svetkey LP, Sacks FM, Obarzanek E, et al. (1999) The DASH Diet, Sodium Intake and Blood Pressure Trial (DASHsodium): rationale and design. DASH-Sodium Collaborative Research Group. I Am Diet Assoc 99, S96-S104.

67. Smith PJ, Blumenthal JA, Babyak MA, et al. (2010) Effects of the Dietary Approaches to Stop Hypertension diet, exercise, and caloric restriction on neurocognition in overweight adults with high blood pressure. Hypertension $\mathbf{5 5}$, $1331-1338$

68. Bayer-Carter JL, Green PS, Montine TJ, et al. (2011) Diet intervention and cerebrospinal fluid biomarkers in amnestic mild cognitive impairment. Arch Neurol 68, 743-752.

69. Panagiotakos D (2008) A priori versus a posterior methods in dietary pattern analysis: a review in nutrition epidemiology. Nutr Bull 33, 311-315.

70. Tinsley HEA \& Tinsley DJ (1987) Uses of factor analysis in counseling psychology research. I Couns Psychol 34, 414-424.

71. Kleinbaum DG, Kupper LL \& Muller KE (1997) Applied Regression Analysis and Other Multivariable Methods, 3rd revised ed. Belmont, CA: Wadsworth Publishing Co., Inc.

72. Akbaraly TN, Archana S-M, Marmot MG, et al. (2009) Education attenuates the association between dietary patterns and cognition. Dement Geriatr Cogn Disord 27, 147-154.

73. Newby PK, Muller D, Hallfrisch J, et al. (2003) Dietary patterns and changes in body mass index and waist circumference in adults. Am J Clin Nutr 77, 1417-1425.

74. Smith ADAC, Emmett PM, Newby PK, et al. (2011) A comparison of dietary patterns derived by cluster and principal components analysis in a UK cohort of children. Eur J Clin Nutr 65, 1102-1109.

75. Samieri C, Jutand M-A, Féart C, et al. (2008) Dietary patterns derived by hybrid clustering method in older people: association with cognition, mood, and self-rated health. $J$ Am Diet Assoc 108, 1461-1471.

76. Corrêa Leite ML, Nicolosi A, Cristina S, et al. (2003) Dietary and nutritional patterns in an elderly rural population in Northern and Southern Italy: (I). A cluster analysis of food consumption. Eur J Clin Nutr 57, 1514-1521.

77. James DCS (2009) Cluster analysis defines distinct dietary patterns for African-American men and women. $J$ Am Diet Assoc 109, 255-262.

78. Pryer JA, Cook A \& Shetty P (2001) Identification of groups who report similar patterns of diet among a representative national sample of British adults aged 65 years of age or more. Public Health Nutr 4, 787-795.

79. Pryer JA \& Rogers S (2009) Dietary patterns among a national sample of British children aged $1 \quad 1 / 2-4 \quad 1 / 2$ years. Public Health Nutr 12, 957-966.

80. Reedy J, Wirfält E, Flood A, et al. (2010) Comparing 3 dietary pattern methods - cluster analysis, factor analysis, and index analysis - with colorectal cancer risk: The NIH-AARP Diet and Health Study. Am J Epidemiol 171 479-487.

81. Hoffmann K, Schulze MB, Schienkiewitz A, et al. (2004) Application of a new statistical method to derive dietary patterns in nutritional epidemiology. Am J Epidemiol 159, 935-944.

82. Schulze MB, Hoffmann K, Manson JE, et al. (2005) Dietary pattern, inflammation, and incidence of type 2 diabetes in women. Am J Clin Nutr 82, 675-684.
83. DiBello JR, Kraft P, McGarvey ST, et al. (2008) Comparison of 3 methods for identifying dietary patterns associated with risk of disease. Am J Epidemiol 168, 1433-1443.

84. Drogan D, Hoffmann K, Schulz M, et al. (2007) A food pattern predicting prospective weight change is associated with risk of fatal but not with nonfatal cardiovascular disease. J Nutr 137, 1961-1967.

85. Hoffmann K, Zyriax B-C, Boeing H, et al. (2004) A dietary pattern derived to explain biomarker variation is strongly associated with the risk of coronary artery disease. $\mathrm{Am} \mathrm{J}$ Clin Nutr 80, 633-640.

86. Liu L, Nettleton JA, Bertoni AG, et al. (2009) Dietary pattern, the metabolic syndrome, and left ventricular mass and systolic function: the Multi-Ethnic Study of Atherosclerosis. Am J Clin Nutr 90, 362-368.

87. McCann SE, McCann WE, Hong C-C, et al. (2007) Dietary patterns related to glycemic index and load and risk of premenopausal and postmenopausal breast cancer in the Western New York Exposure and Breast Cancer Study. Am J Clin Nutr 86, 465-471.

88. McNaughton SA, Mishra GD \& Brunner EJ (2009) Food patterns associated with blood lipids are predictive of coronary heart disease: the Whitehall II study. Br J Nutr 102, 619-624.

89. Nettleton JA, Steffen LM, Schulze MB, et al. (2007) Associations between markers of subclinical atherosclerosis and dietary patterns derived by principal components analysis and reduced rank regression in the Multi-Ethnic Study of Atherosclerosis (MESA). Am J Clin Nutr 85, 1615-1625.

90. Nöthlings U, Murphy SP, Wilkens LR, et al. (2008) A food pattern that is predictive of flavonol intake and risk of pancreatic cancer. Am J Clin Nutr 88, 1653-1662.

91. Weikert C, Hoffmann K, Dierkes J, et al. (2005) A homocysteine metabolism-related dietary pattern and the risk of coronary heart disease in two independent German study populations. J Nutr 135, 1981-1988.

92. Gu Y, Nieves JW, Stern Y, et al. (2010) Food combination and Alzheimer disease risk: a protective diet. Arch Neurol 67, 699-706.

93. Bountziouka V, Tzavelas G, Polychronopoulos E, et al. (2011) Validity of dietary patterns derived in nutrition surveys using a priori and a posteriori multivariate statistical methods. Int J Food Sci Nutr 62, 617-627.

94. Slattery ML (2010) Analysis of dietary patterns in epidemiological research. Appl Physiol Nutr Metab 35, 207-210.

95. Bowman GL, Shannon J, Ho E, et al. (2011) Reliability and validity of food frequency questionnaire and nutrient biomarkers in elders with and without mild cognitive impairment. Alzheimer Dis Assoc Disord 25, 49-57.

96. Debette S, Seshadri S, Beiser A, et al. (2011) Midlife vascular risk factor exposure accelerates structural brain aging and cognitive decline. Neurology 77, 461-468.

97. Luchsinger JA \& Gustafson DR (2009) Adiposity and Alzheimer's disease. Curr Opin Clin Nutr Metab Care 12, 15-21.

98. Xu WL, Atti AR, Gatz M, et al. (2011) Midlife overweight and obesity increase late-life dementia risk: a population-based twin study. Neurology 76, 1568-1574.

99. Eskelinen MH, Ngandu T, Tuomilehto J, et al. (2011) Midlife healthy-diet index and late-life dementia and Alzheimer's disease. Dement Geriatr Cogn Dis Extra 1, 103-112.

100. Imamura F \& Jacques PF (2011) Invited Commentary: dietary pattern analysis. Am J Epidemiol 173, 1105-1108.

101. Kaaks R, Riboli E, Estève J, et al. (1994) Estimating the accuracy of dietary questionnaire assessments: validation in terms of structural equation models. Stat Med 13, 127-142. 